\title{
Modelling of a wind power turbine
}

\section{Document Version}

Submitted manuscript

Link to publication record in Manchester Research Explorer

\section{Citation for published version (APA):}

Christ, F., \& Abeykoon, C. (2015). Modelling of a wind power turbine. In host publication (pp. 205-210)

\section{Published in:}

host publication

\section{Citing this paper}

Please note that where the full-text provided on Manchester Research Explorer is the Author Accepted Manuscript or Proof version this may differ from the final Published version. If citing, it is advised that you check and use the publisher's definitive version.

\section{General rights}

Copyright and moral rights for the publications made accessible in the Research Explorer are retained by the authors and/or other copyright owners and it is a condition of accessing publications that users recognise and abide by the legal requirements associated with these rights.

\section{Takedown policy}

If you believe that this document breaches copyright please refer to the University of Manchester's Takedown Procedures [http://man.ac.uk/04Y6Bo] or contact uml.scholarlycommunications@manchester.ac.uk providing relevant details, so we can investigate your claim.

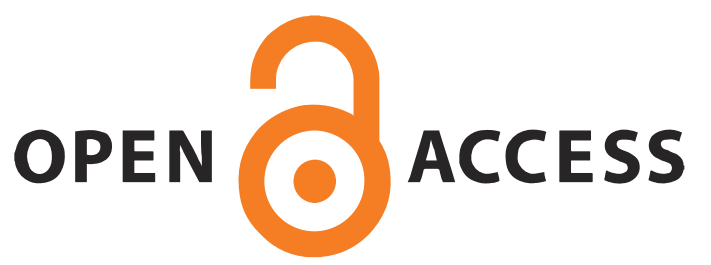




\section{Modelling of a Wind Power Turbine}

\section{Fabian Christ}

Division of Applied Science, Computing and Engineering, Glyndwr University, Mold Road, LL11 2AW, Wrexham, United Kingdom

Email: f-christ@gmx.de

\begin{abstract}
Due to the predicted scarcity of the fossil fuels and their adverse effects to the environment, currently renewable energy generation is a major focus of the power and energy sector. Wind energy is one of the potential and rapidly growing sources of green energy. This is particularly due to the cost of the wind energy production has reduced by a factor of more than five over the last two decades. Moreover, wind turbines can cover a wide range of power outputs from $50 \mathrm{~W}$ to $5 \mathrm{MW}$ and beyond compared to other green energy sources. This study is aimed to model a horizontal axis wind power turbine theoretically and computationally. Initially, theoretical calculations were carried out by considering a few specific case studies with different power outputs. Then, the same case studies were considered for a computational fluid dynamics (CFD) analysis. Theoretical results show that the modelled wind turbine reaches a power output of 4.4 MW. Moreover, the theoretically calculated thrust and torque show a good agreement with the values obtained from CFD with a deviation of $2.9 \%$ only which confirms the accuracy of results. Therefore, the findings of this work should be useful in investigating ways to improve the performance of horizontal axis wind turbines.
\end{abstract}

Keywords-Wind power generation; Horizontal axis turbines; Power coefficient; Tip speed ratio; Modelling; CFD.

\section{INTRODUCTION}

Wind is a natural and renewable source of energy. The greatest potential of wind energy is that it is readily available throughout the year and almost all over the world. The UK's average mean wind speed map is shown in Figure 1.

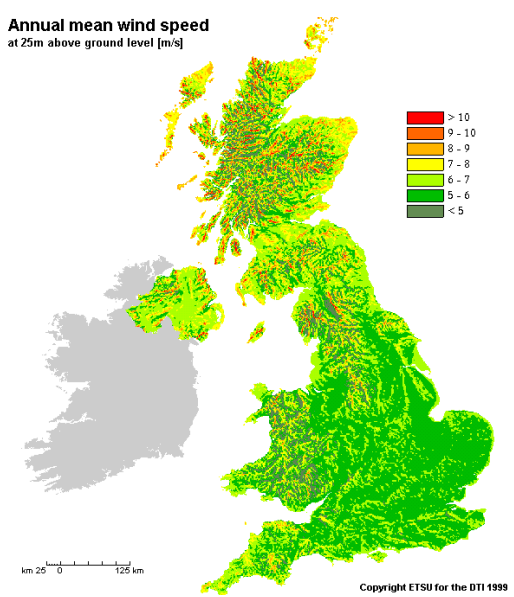

Fig.1: Annual mean wind speed in the UK [1]

\author{
Chamil Abeykoon \\ Division of Applied Science, Computing and Engineering, \\ Glyndwr University, Mold Road, LL11 2AW, Wrexham, \\ United Kingdom \\ E-mail: c.abeykoon@glyndwr.ac.uk
}

In contrast, solar energy can be used efficiently only in the summer for many of the countries. Wind energy is competing with other energy sources such as solar, nuclear, tidal current, wave, geothermal, etc. Over the last 15 years, the use of wind energy has increased rapidly as shown in Figure 2 and only during the period from 2003 to 2007, it is an increment of 25\%. [2]. Currently, the Asia is leading the wind energy generation followed by the Europe and the North America. Moreover, the predicted future wind power capacity in the globe is presented in Figure 3.

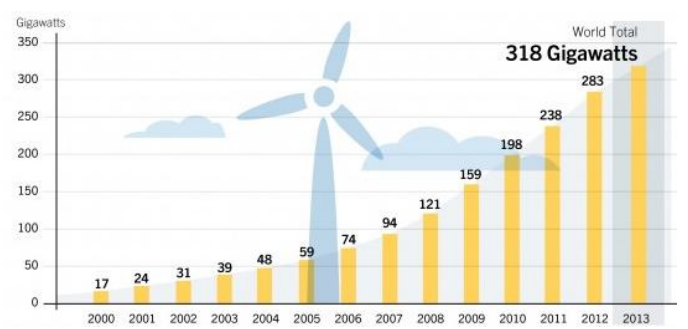

Fig. 2: Increase of global wind power capacity from year 2000-2013 [2]

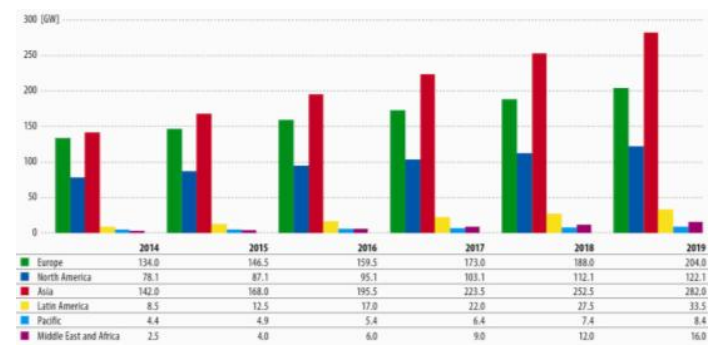

Fig. 3: Cumulative market forecast by region 2014-2019 [3]

As shown in Figure 4, the Europe's total wind power share of the total installed power capacity has increased dramatically from $2.4 \%$ to $14.5 \%$ over the period of 2000 to 2014 [3].

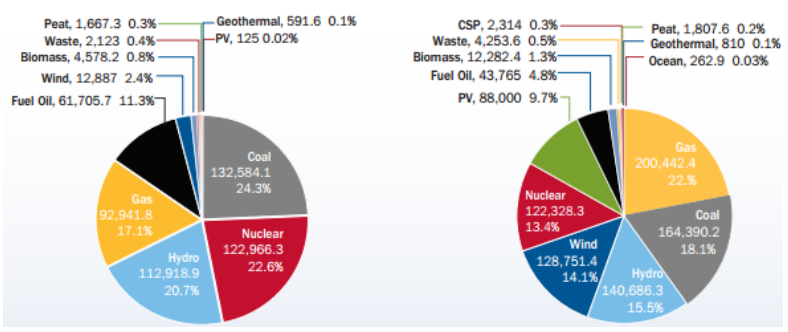

Fig. 4: Installed power capacity within the Europe in MW - Left in year 2000, Right in year 2014 [3] 
Thanks to the numerous research and development, the typical size of wind power turbines has been increased by a factor of 100 over last two decades. Therefore, wind power plants with huge capacities are currently available (in rural areas and also in offshore) and also this sector is expecting further improvements to cater the future energy demand. In the initial stage of this work, an investigation was made on the basic principles of harnessing wind energy. The major focus of this work was made on horizontal axis wind turbines with three blades due to their wider availability. In the second stage, theoretical calculations were performed to determine the power output of wind turbines with different rotor radii, blade angles and also over different wind speeds. Then, an efficient design was selected based on the theoretical results and the selected design was modelled with CFD as well. Eventually, a comparison was made between theoretical and CFD results.

\section{A. Wind Turbine Types}

The technology of fabricating wind turbines and harvesting wind energy has been achieved a vast improvement over the last few decades. The important facts and millstones of this development process have been presented by European Wind Energy Association (EWEA) [2] and Kaldellis et al. [4].

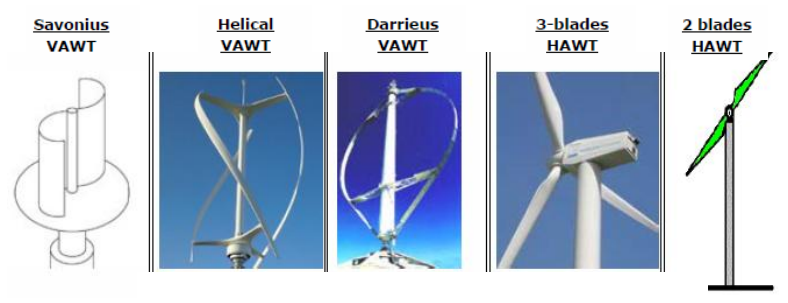

Fig. 5: Wind turbine types [4]

Typical wind turbines (WT) can be categorized into two major groups as horizontal axis (HA) and vertical axis turbines (VA) as shown in Figure 5. Of these two types, horizontal axis is the most commonly used type and they are available with two or three blades. Wind turbines with three blades are high in efficiency and also they are less in noise compared to two blade turbines [2]. Turbines with two blades run at a higher tip speed than three blades and this causes in high noise levels. Work carried out by Yang et al. [6] explored on the structure and the common faults of wind turbines. More information on wind power generation can be found in the literature $[2,6-8]$.

\section{B. A Typical Horizontal Axis Wind Power Plant - Components and Operations}

A wind turbine consists of a rotor, a nacelle and tower which are built on a foundation as shown in Figure 6. The rotor is composed of a hub and blades, which are pitch controlled. The rotor catches the wind energy which rotates the main shaft (i.e., the low speed shaft). The low speed shaft is connected with a generator shaft (i.e., direct drive) or with a high speed shaft through a gear box. The main task of the gearbox is to transform the energy with the desired speed of the generator which then transforms the mechanical energy into the electrical energy. Currently, different types of generators are available in the market (e.g., squirrel cage or doubly-fed induction generators, double-fed asynchronous generators, wound field or permanent magnet synchronous generators). The most commonly used in wind turbines is the double-fed asynchronous generator due to its power electronic converter.

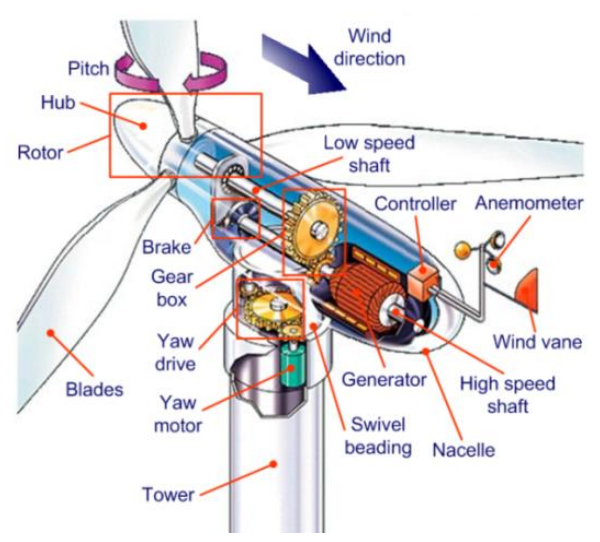

Fig. 6: Components of a horizontal axis wind turbine [5]

Wind turbines operate in variable speeds or with a fixed speed. Hence, the wind turbine generator systems (WTGS) are available in two types: fixed speed WTGS and variable speed WTGS. Fixed speed WTGS is directly coupled to the grid and those bring some good properties such as rugged construction, low cost, less maintenance and the simple operation. The rotor speed has just a variation of 1-2\% of the rated speed. Usually, constant speed wind turbines are mechanically more robust than variable speed turbines. Since the rotor speed is constant, wind speed fluctuations can create heavy vibrations on the rotors. This results in higher structural loads than with variable speed systems. Usually, the fixed speed is achieved by braking the system until the desired speed is achieved. If strong wind turbulences emerge or the wind speed increases, these can be easily regulated by stall or pitch control. It is just a connection between the grid and rotor when the rotor runs at a fixed speed. Variable speed system has one main advantage as they can generate more energy for a specific wind speed range compared to a fixed speed turbine. The mechanical stress that the components may be subjected to is less because the rotor acts like a flywheel. Therefore, it is possible to store the energy temporarily as a buffer. Moreover, the noise level is much lower in variable speed systems. The rotational speed is low as the wind turbine can work at lower wind speeds as well. To achieve variable speed operation, the mechanical rotor speed and the electrical frequency of the grid must be decoupled. For this purpose, a special generator should be employed. Hence, doubly fed induction generators with a power electronic converter are used in variable speed wind turbines [6-8].

The variable speed technology brings better output power quality to the grid. The rotor is connected with the grid as to deliver the power only at a specific speed range. The architecture of a typical three blade wind turbine is that a low speed shaft is connected between the blade shaft and a gearbox. The gearbox is connected to the generator through a high speed shaft. To get high quality power output the electrical control system regulates the generator. The converter and transformer transform the power to the grid. The 
control system is called the command centre, because it measures the direction of the wind for the yaw system. The yaw system turns the nacelle into the direction of the wind to use the wind energy by maximum efficiency. As shown in Figure 6, it is divided into yaw drive and yaw motor. Also, the control system controls the electric power output by stabilizing it with the pitch system. The controller is connected to an anemometer and a wind vane. While an anemometer gives the wind speed, a wind vane provides the wind direction. Based on this information, the braking system can stop the whole wind turbine system as required. The brake should also be used in maintenance work. The tower and foundation carry the wind turbine and the tower should have a certain height to gain the highest possible wind energy.

\section{Downwind and Upwind Rotor}

A wind turbine can be designed with a downwind or an upwind rotor [8]. A turbine with a downwind rotor does not need a yaw system hence it has a free yaw. It turns the rotor automatically in the direction of the wind. However, if the wind changes abruptly or suddenly, the system may perform badly. Downwind rotor does make more noise than upwind rotor. Yaw controlled upwind rotors with three blades have no this problems. That is the reason why upwind rotors dominate in wind power plants when an active pitch control is used.

\section{Stall and Pitch Control}

In general, two options are available to regulate the rotor power in high wind cycles: stall regulation and pitch regulation. The stall regulated turbines absorb the wind power with their aerodynamic design. The most of the modern wind turbines use active pitch control; and it can be separated into hydraulic and electrical pitch. Electrical pitch is much used because it is more flexible and is easy to control. If a wind turbine uses pitch regulation (or known as pitching the blades), their blades can turn electrically around the axis of the blades. The pitch control has the task to use the best angle for the right wind speed to get the optimum power output. In other words, the pitch angle helps the blades to maximize the energy. Only a small change of the pitch angle can have a huge effect on the power output of the wind turbine $[2,8]$. The main objective of both control options is the same, to control the output power in high wind speeds. The pitch control system has four tasks: (i) to minimize the dynamic and static loads on the blades by changing the angle, (ii) when the wind speed is more than the rated speed it has to steady the output power of the generator, (iii) use the blade back as an aerodynamic brake to stop the rotor if required, (iv) damping out the rotor vibrations to minimize the mechanical load.

\section{Design Of The Wind Power Plant}

\section{A. Power Output}

The information provided in the previous work [4- 10] was used in calculating the power output of horizontal axis wind turbines with three blades. An upwind rotor is considered in the design since downwind rotors may perform badly in high wind speeds. Usually, wind turbines are controlled with a pitch control mechanism over variable wind speeds and directions. Thus, a variable speed turbine which allows a good energy intake was chosen in this work. For this case study, diameter $(d)$ of the rotor was chosen as $100 \mathrm{~m}$ and also air density $(\rho)$ as $1.225 \mathrm{~kg} / \mathrm{m}^{3}$. Then, the wind tower height and the rotor swept area are given by eq. (1) and (2), respectively.

$$
\begin{aligned}
& \text { Height: } h=2.7936 \times d^{0.766 a}=95.23 \mathrm{~m} \\
& \text { Rotor swept area: } A=r^{2} \times \pi=7853.98 \mathrm{~m}
\end{aligned}
$$

Every part that moves has a kinetic energy. The formula for the kinetic energy $U$ of is given by:

$$
U=\frac{1}{2} \times m \times v_{W}^{2}
$$

where $m$ is the mass $[\mathrm{kg}]$ and $v_{w}$ is the wind speed $[\mathrm{m} / \mathrm{s}]$. It is directly proportional to the square of the velocity $v$ and mass $m$ of the body. This also applies to a body of air when the wind flowing through an area $A$. If the surface is normal to the wind direction, the energy flux $P_{W}$ which is transported by the wind through the surface is calculated by:

$$
P_{W}=\frac{1}{2} \times p \times A \times v_{W}^{a}
$$

Since the power of the wind increases with a cubic power of the wind speed, a small increase in speed causes a large capacity gain. The theoretically maximum available wind power is:

$$
P_{T}=\frac{1}{2} \times c_{p} \times p \times A \times v_{W}^{a}
$$

Wind turbines cannot harness the full amount of energy gathered in a flowing wind. The fraction of the power that can be extracted from wind through a wind turbine is usually given by the symbol $c_{p}$ (known as the power coefficient) and this describes the efficiency of a wind turbine. The power coefficient is different for each wind turbine type and also this depends on the parameters such as tip speed ratio, wind speed/pattern.

$$
c_{p}=\frac{P_{T}}{P_{W}}
$$

The wind has to pass the blades to rotate the rotor and hence the speed of the wind cannot be zero behind the turbine blades. The incoming wind speed $v_{l}$ is larger than the wind speed $v_{2}$ behind the turbine. The reported maximum for all types wind turbines is that only $59.3 \%$ of the kinetic energy of the wind can be converted into mechanical energy. Welldesigned wind turbines generally fall in the range of $35 \%-$ $45 \%$ [7].

$$
\begin{aligned}
& \text { Betz coefficient: } \quad v_{2}=\frac{1}{a} \times v_{1} \\
& c_{p}=\frac{P_{Y}}{P_{W}}=\frac{\left(v_{1}+v_{2}\right) \times\left(v_{1}^{2}-v_{2}^{2}\right)}{2 \times v_{1}^{3}}=\frac{16}{27}=0.5926=59.3 \%
\end{aligned}
$$

That is the reason why the maximum power coefficient is defined as: $c_{\text {pmax }}=0.59$. The tip speed ratio $\lambda$ indicates how fast the blade tips are relative to the wind speed. 


$$
\begin{aligned}
\lambda=\frac{v_{\text {tip }}}{w_{V q}} & (9) & v_{\text {tip }}=\frac{f \times \pi \times d}{60} \\
\lambda=\frac{w_{r} \times r}{w_{V}} & (11) & \omega_{r}=\frac{2 \times \pi \times f}{60}
\end{aligned}
$$

where, $v_{\text {tip }}$ is the blade tip speed $[\mathrm{m} / \mathrm{s}], \omega_{r}$ is the angular velocity [radians/sec], and $f$ is the revolutions per minute [rpm]. To calculate the $c_{p}$ for a variable speed wind turbine, the values of pitch angle $\beta$ and the tip speed ratio $\lambda$ are required [10].

$$
\begin{gathered}
\lambda_{i}=\frac{1}{\frac{1}{\lambda+0.008 \times \beta}-\frac{0.0085}{\beta^{3}+1}} \\
c_{p}\left(\lambda_{i} \beta\right)=0.73 \times\left[\frac{151}{\lambda_{1}}-0.58 \beta-0.002 \beta^{2.14}-13.2\right] \times \theta^{\frac{-124}{24}}
\end{gathered}
$$

Figure 7 shows the power coefficient as a function of pitch angle and tip speed ratio. The highest $c_{p}$ is 0.44 with a tip speed ratio of 8 and a zero pitch angle. The diagram shows that the power coefficient decreases as the pitch angle increases. Hence, it possible to achieve a high power by maintaining the pitch angle and hence some wind turbines use a braking system to control the blade angle.

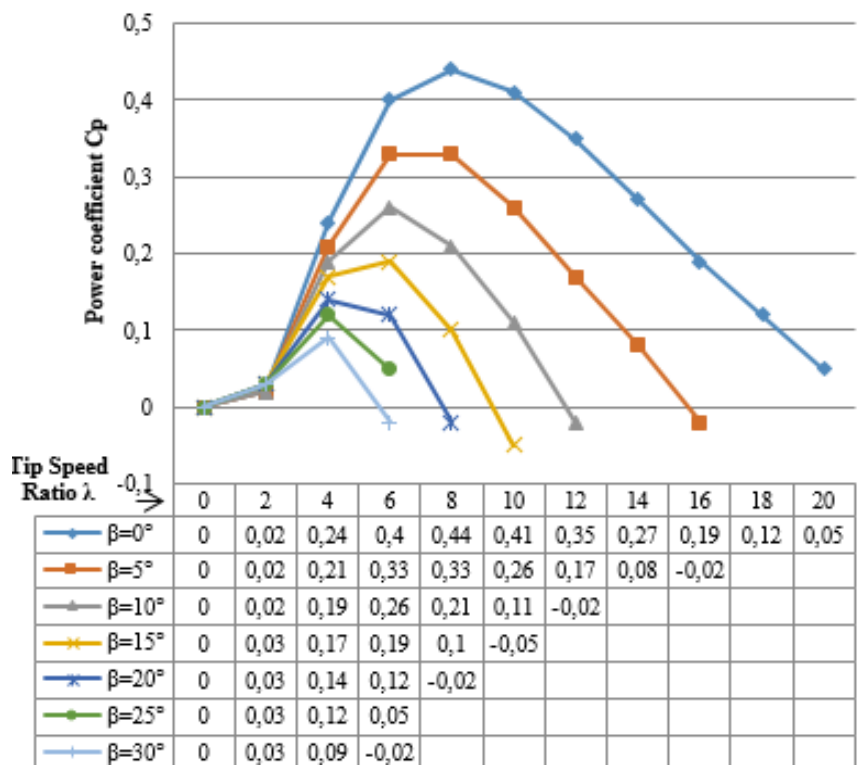

Fig. 7: Power coefficient $\mathrm{Cp}$ at different pitch angles $\beta$ and tip speed ratios $\lambda$

After choosing the best parameters to generate the maximum possible power, the power outputs with different wind speeds from 0 to $30 \mathrm{~m} / \mathrm{s}$ were calculated in Mathcad 15 . It was assumed that the generator attached to the wind turbine has its cut-in speed at $4 \mathrm{~m} / \mathrm{s}$ and its cut-out speed at $24 \mathrm{~m} / \mathrm{s}$. The calculated power output for the different wind speeds with the used pitch angle and the resulting power coefficient is given in Table 1.

The actual power output $\left(P_{O}\right)$ of the wind turbine is:

$$
P_{0}=\eta_{g b} \times \eta_{g e} \times P_{T}
$$

where $\eta_{g b}$ is the gearbox efficiency (depends on the gearbox type and could be as high as 95\%) and $\eta_{g e}$ is the generator efficiency $(80 \%$ or possible more for a grid-connected induction generator).
The cut-in speed is the wind speed at which the generator starts to produce electricity. In this case, it is at $4 \mathrm{~m} / \mathrm{s}$ with a power of 0.1 MW. Afterwards, the power output is increasing gradually with the wind speed until the wind speed reaches 14 $\mathrm{m} / \mathrm{s}$ (at this speed the power output is $4.4 \mathrm{MW}$ ). Also at this wind speed the generator reaches its maximum power production. As the wind speed go above $14 \mathrm{~m} / \mathrm{s}$, the wind turbine has to pitch its blade angle to control the power output. Therefore, the wind turbine can hold this maximum power until the wind speed reaches its cut-out speed $(24 \mathrm{~m} / \mathrm{s})$. At the cut-out wind speed the blade pitch angle reaches its maximum of $30^{\circ}$ and there will be no power generation at the wind speeds above the cut-out speed as shown in Figure 8. Table 1 and Figure 7 show that the power coefficient is decreasing as pitch angle is increasing.

TABLE I: POWER OUTPUT WITH VARIOUS WIND SPPED AND PTICH ANGLES

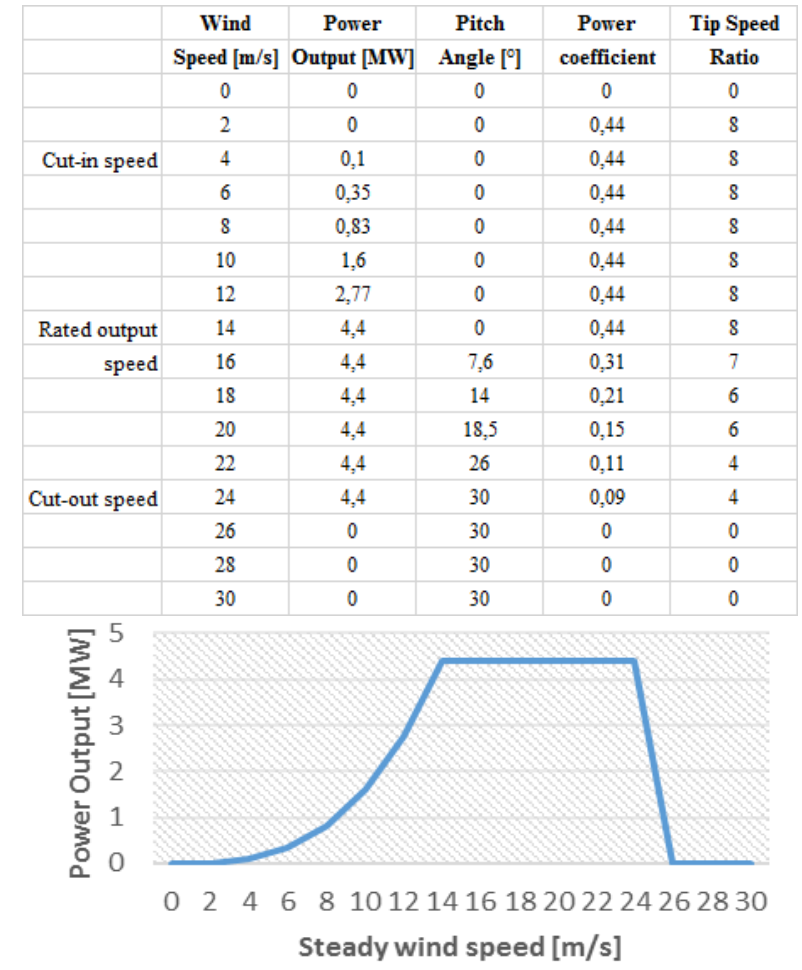

Fig. 8: Power output with steady wind speed

As shown in Figure 8, the wind turbine produces energy only within the wind speed range of $4-24 \mathrm{~m} / \mathrm{s}$ only. Also, it reaches the best power output in the speed range of 14-24 m/s.

\section{B. Wind Turbine Blades}

Previous studies [12-14] provide valuable information on the design of wind turbine blades. The key parameters of a wind turbine design are the number of blades, the aerofoil shape, the chord distribution and the twist distribution. The design process should start with determining the rotor diameter based on the conditions of site and $P=\frac{1}{2} \times c_{p} \times \eta \times \rho \times A \times v_{w}^{a}$. The chosen diameter in this work is $100 \mathrm{~m}$. Then, a tip speed ratio should be chosen where it should be in the range of 
$4<\lambda<10$ for the wind turbines in electrical power generation. Hence, the tip speed ratio $(\lambda)$ was chosen as 8 .

The next step is to choose the number of blades $B$, which was chosen as three in this work. Then, it is possible to select the shape of the aerofoil. In fact, different aerofoils can be used at different sections of the blade. A thick aerofoil is better for the root of the blade to provide better strength [14]. In this work, four NACA aerofoils from the NACA 4 digit aerofoil database are analysed with the CFD software ANSYS 15 to get the lift and drag values with different angles of attack. According to the published literature on NACA 6412, it can reach a very high lift coefficient as shown in Figure 9.

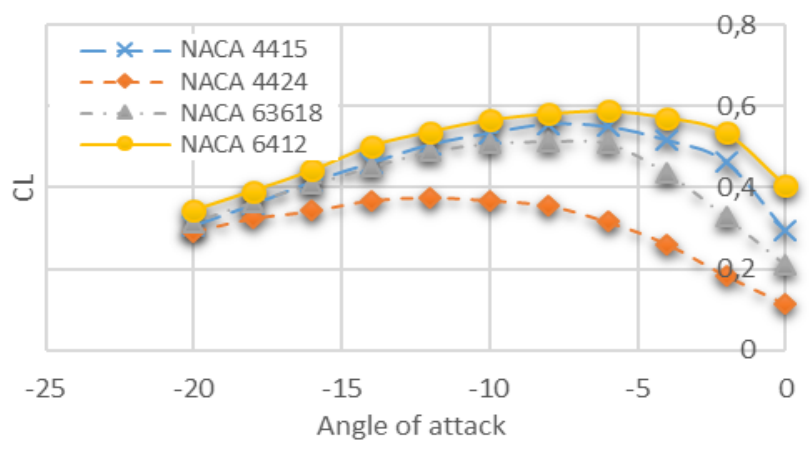

Fig. 9: Lift coefficient vs Angle of Attack for the selected aerofoils

According to the results of this work as well, the NACA 6412 shows the best performance. The NACA 4415, which is thicker, has also good lift coefficients. Hence, the NACA 4415 is used for the root of the blades and the NACA 6412 for the wing and the tip. For the design, blade has to be divided into $N$ elements as shown in Figure 10. Usually 10 to 20 elements would be used. Rough calculations of the relative flow angle in to blades $(\gamma)$ and the chord length $C$ is shown below: [14]

$$
\gamma=90^{\circ}-\frac{2}{a} \tan ^{-1}\left(\frac{1}{l_{r}}\right)
$$

where $\lambda_{\mathrm{r}}$ is the tip speed ratio of the local radius.

$$
C=\frac{8 \pi r \cos y}{3 B \lambda_{r}}
$$

The widest chord is usually given by:

$$
r=0.2 \times R
$$

where $R$ is the blade radius and $r$ is the local radius of the blade element. The blade in this work has the greatest chord length at $10 \mathrm{~m}$. The complete turbine with blades and the hub were modelled using Solid Works 2014 and shown in Figure 10. In optimizing the blade, the Element Momentum Theory can be used by considering important parameters such as the axial induction factor $(a)$, the annular induction factor $\left(a^{\prime}\right)$ and more information on this can be found in the literature [10-12]. The calculation of the optimum blade is an iterative process and the designer has to spend a lot of time to refine the chord and twist distribution to get an acceptable solution.
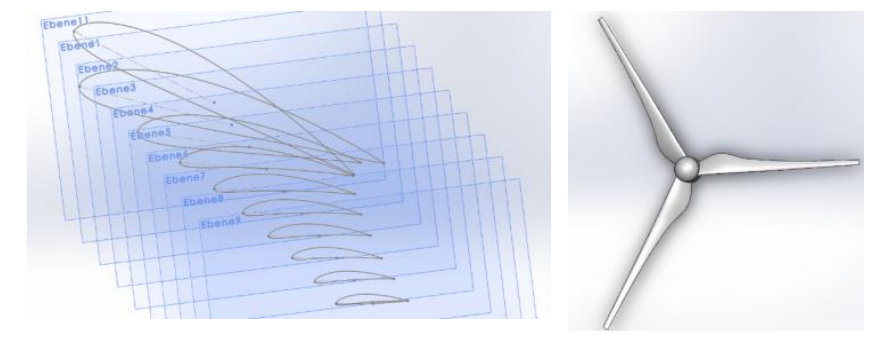

Fig. 10: Left- Blade elements with different chord lengths and inflow angles, Right - Modelled Wind Turbine in Solid Works

The momentum theory gives:

$$
\begin{aligned}
& \sigma^{\prime}=\frac{B \times C}{2 \times \pi \times r} \\
& Q=\frac{2}{\pi} \cos ^{-1}\left[\exp \left\{-\left(\frac{B / 2(1-Y / R)}{\left(r_{j} / R\right) \cos \gamma}\right)\right\}\right] \\
& a=\frac{\sigma^{*}\left(C_{L} \sin \gamma+C_{D} \cos \gamma\right)}{4 Q(\cos \gamma)^{2}+\sigma^{\prime}\left(C_{L} \sin \gamma+C_{D} \cos \gamma\right)} \\
& a^{\prime}=\frac{(1-a) \sigma^{\prime}\left(c_{L} \sin \gamma+C_{D} \cos \gamma\right)}{4 Q(\cos \gamma)^{2}+\sigma^{\prime}\left(C_{L} \sin \gamma+C_{D} \cos \gamma\right)} \\
& F_{x}=\sigma-\pi \rho \frac{v_{W}^{2}(1-a)^{2}}{(\cos \gamma)^{2}}\left(C_{L} \sin \gamma+C_{D} \cos \gamma\right) r d_{\gamma} \\
& T=\sigma-\pi \rho \frac{v_{W}^{*}(1-a)^{2}}{(\cos \gamma)^{2}}\left(C_{L} \cos \gamma+C_{D} \sin \gamma\right) r^{2} d_{\gamma}
\end{aligned}
$$

where $T$ is the thrust, $Q$ is the torque, $d r$ is the ring section of the rotor disc, $\sigma^{\prime}$ is the local solidity and $Q$ is the blade correction factor.

TABLE II: CALCULATED PARAMETERS

\begin{tabular}{|l|l|l|l|l|}
\hline $\begin{array}{l}\text { Radius } \\
\mathbf{r}[\mathbf{m}]\end{array}$ & $\begin{array}{l}\text { Thrust } \\
\mathbf{F}_{\mathbf{x}}[\mathbf{N}]\end{array}$ & $\begin{array}{l}\text { Torque } \\
\mathbf{T}[\mathbf{N m}]\end{array}$ & $\begin{array}{l}\text { Lift } \\
\text { coefficient } \mathbf{C}_{\mathbf{L}}\end{array}$ & $\begin{array}{l}\text { Drag } \\
\text { coefficient } \mathbf{C}_{\mathbf{D}}\end{array}$ \\
\hline 10 & 18909 & 58720 & 1.4 & 0.1 \\
\hline 15 & 28417 & 102746 & 1.5 & 0.04 \\
\hline 20 & 38041 & 144745 & 1.59 & 0.022 \\
\hline 25 & 47478 & 182416 & 1.57 & 0.017 \\
\hline 30 & 56321 & 217400 & 1.45 & 0.013 \\
\hline 35 & 64275 & 245217 & 1.3 & 0.012 \\
\hline 40 & 72010 & 270776 & 1.25 & 0.012 \\
\hline 45 & 74717 & 279416 & 1.21 & 0.011 \\
\hline
\end{tabular}

With the torque values calculated, total power from each annulus can be determined.

$$
P_{a}=w_{Y} \times T
$$

Then, the total power from the rotor is given by:

$$
P=\int_{r_{h}}^{R} P_{a} \times d_{y}=\int_{r_{h}}^{R} w_{\gamma} T \times d_{r}
$$

where $r_{h}$ is the radius of the hub which is $3.5 \mathrm{~m}$ in this work. $R$ is the total radius of the wind turbine blade. Table 3 shows the total power from each annulus and the total power from the rotor for each radius of the blade. 
TABLE III: TOTAL POWER OF GENERATED FROM THE TURBINE

\begin{tabular}{|l|l|l|}
\hline $\begin{array}{l}\text { Radius } \\
\mathbf{r}[\mathbf{m}]\end{array}$ & $\begin{array}{l}\text { Total Power from } \\
\text { each annulus } \mathbf{P}_{\mathbf{a}}[\mathbf{k W}]\end{array}$ & $\begin{array}{l}\text { Total Rotor Power } \\
\mathbf{P}[\mathbf{k W}]\end{array}$ \\
\hline 10 & 94 & 4368 \\
\hline 15 & 164 & 7644 \\
\hline 20 & 232 & 10781 \\
\hline 25 & 292 & 13572 \\
\hline 30 & 348 & 16175 \\
\hline 35 & 392 & 18244 \\
\hline 40 & 433 & 20146 \\
\hline 45 & 477 & 20789 \\
\hline
\end{tabular}

\section{CFD MODELLING}

In CFD, an accurate mesh is necessary to achieve acceptable results. The geometry and mesh of the wind turbine is done by considering previous works. After importing the boundary conditions into ANSYS-Fluent, the simulation was performed and the pattern of streamlines across the blades is shown in Figure 11. Then, the mechanical power can be calculated by using the achieved torque value. In this work, the theoretically calculated torque is $279416 \mathrm{Nm}$ where the torque achieved from CFD is $287649 \mathrm{Nm}$.

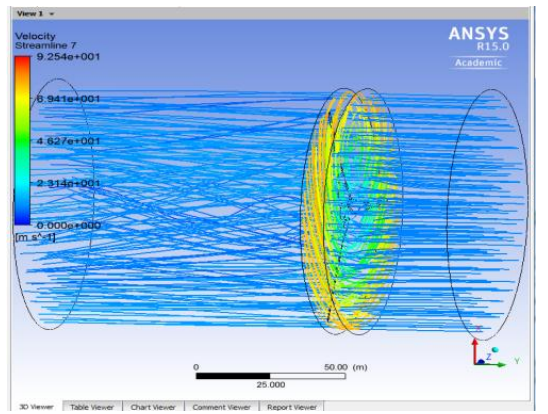

Fig. 11: The pattern of streamlines shown in CFD Results

\section{CONCLUSION AND FUTURE WORKS}

A design of a horizontal with turbine was performed theoretically and in CFD. The designed wind power turbine has a rotor diameter of $100 \mathrm{~m}$ where its height is $95.23 \mathrm{~m}$. The proposed wind turbine reaches its maximum power output within the wind speed range of 14-24 m/s. Generally, the wind turbine reaches its maximum at $14 \mathrm{~m} / \mathrm{s}$ and then it can hold its maximum power until the speed reaches to $24 \mathrm{~m} / \mathrm{s}$ by pitching the blades from 0 to $30^{\circ}$. The maximum possible output power of the proposed design is $4.4 \mathrm{MW}$. As the wind speed increases the power output increases while the power output decreases as the blade pitch angle increases. According to the theoretical results, the torque generated by the proposed wind turbine is $279416 \mathrm{Nm}$ where the CFD results showed that it is $287649 \mathrm{Nm}$ for the same design. Hence, the theoretical and CFD results are in good agreement with a small deviation of $2.9 \%$. Generally, this type of models can be used to evaluate the performance of wind turbines at wide range of operating conditions to achieve optimum power generating performance prior to their fabrication. In future work, various sizes of blade diameters will be considered over wide operating conditions to make a better comparison. Moreover, the study will be extended to explore the effects different shape of aerofoils and different types of materials for constructing blades to choose the best possible combination.

\section{REFERENCES}

[1] Wind speed map of the UK, Available at: http://www.esru.strath.ac.uk/EandE/Web_sites/0304/wind/content/ukwindspeedmap.html, [Last viewed: 12/03/2015].

[2] European Wind Energy Association, "Wind Energy - The Facts", Earthscan, Brussels, 2009.

[3] Pineda, Wilkes, EWEA (2015) Wind in power: 2014 European statistics, Earthscan

[4] K. Kaldellis and D. Zafrakis, "The wind energy (r)evolution: A short review of a long history", Renewable Energy, vol. 36 (7), pp. 1887 1901, 2011

[5] M.G.Molina and J.G. Alvarez, (2014) "Technical and Regulatory for Grid Connection of Wind Generation, Wind Farm, Technical Regulations, Potential Estimation and Siting Assessment", Dr. G.O Suvire (Ed.), http://www.intechopen.com/books/wind-farm-technicalregulations-potential-estimation-and-siting-assessment/technical-andregulatory-exigencies-for-grid-connection-of-wind-generation [Last viewed 13/03/15

[6] M. Yang, H. Chengbing and F. Xinxin, "Institutions Function and Failure Statistic and Analysis of Wind Turbine", Internationa Conference on Applied Physics and Industrial Engineering, vol. 24, Part A, pp 25-30, 2012

[7] J. Chen, D. Jiang, "Study on Modeling and Simulation of Non-grid connected Wind Turbine", IEEE Conf. World Non-Grid-Connected Wind Power and Energy Conference, pp 1 - 5, 2009

[8] M. Óskarsdóttir, "A General Description and Comparison of Horizontal Axis Wind Turbines and Vertical Axis Wind Turbines", Faculty of Industrial Engineering, Mechanical Engineering and Computer Science School of Engineering and Natural Sciences University of Iceland Reykjavik 2014

[9] S. M. Muyeen, J. Tamura and T. Murata, "Stability Augmentation of a Grid-connected Wind Farm", 1st ed., Springer, pp 23 - 65, 2009

[10] T. Al-Shemmeri \& Ventus Publishing ApS, "Wind Turbines", E-book, bookboon.com, 2010

[11] J.G. Slootweg, S.W.H. de Haan, W.L. Kling and H. Polinder, "Genera Model for Representing Variable Speed Wind Turbines in Power System Dynamics Simulations", IEEE Transaction on Power Systems, vol. 18 (1), pp. 144-151, 2003

[12] J. Schubel and R. Crossley, "Wind Turbine Blade Design", Faculty Engineering, University Nottingham, Energies, 2012

[13] H. Khadimallah, J.Y. Pradillon, O. Shah and M. Tarfaoui, "Effect of spars cross-section design on dynamic behavior of composite wind turbine blade: modal analysis", $4^{\text {th }}$ International Conference on Power Engineering, Energy and Electrical Drives, pp. 1006-1011, 2013

[14] G. Ingram, "Wind Turbine Blade Analysis using the Blade Momentum Method", Durham University, 2011

[15] H. Cao, "Aerodynamics Analysis of Small Horizontal Axis Win Turbine Blades by Using 2D and 3D CFD Modelling", School of Computing, Engineering and Physical Science, University of Central Lancashire, Preston, 2011

[16] X. Chen, "Optimization of Wind Turbine Airfoils/Blades and Wind Farm Layouts", Washington University, St. Louis, 2014

[17] M. Chandrala, A. Choubkey and B. Gupta, "Aerodynamic Analysis of Horizontal Axis Wind Turbine Blade", IJERA International Journal of Engineering Research and Application, vol. 2 (6), pp. 1244-1248, 2012

[18] K. Cox and A. Echtermeyer, "Structure design and analysis of a 10MW wind turbine blade", Energy Procedia, Deep Sea Offshore Wind R\&D Conference, vol 24, pp. 194-201, 2012

[19] A.Y. Mokhetar, E. Yohana and T.S. Utomo, "The Aerodynamics Analysis of Airfoils for Horizontal Axis Wind Turbine Blade using Computational Fluid Dynamics", ejournal, Mechanical Engineering Deparment, Diponegror University, Rotasi, vol 16 (3), pp. 23-30, 2014.

[20] G. Kumar, R.K. Aggrawal and A. Kumar, "Design criteria and CFD analysis of a small wind turbine installed at Banihal top in snow bound high altitude area", IEEE Non-Conventional Energy, pp. 180-183, 2014. 